\title{
Real-time environmental information for the public and public safety organisations in case of flood events
}

\author{
S. Gottwald \& P. Antoch \\ PSI Environmental Disaster Protection Unit, Germany
}

\begin{abstract}
Recent flood events across Europe have resulted in the development of new applications for high water situations. Real-time environmental monitoring systems prove increasingly valuable while meteorological conditions are changing worldwide. The 2005 and 2006 floods in southern and eastern Germany showed the importance of fast reaction in civil protection. The period needed for alerting the public can be significantly cut by real-time systems. These have to be embedded in a communication infrastructure with clearly defined responsibilities, short information paths, and the acceptance of contemporary technologies to help mitigate the disastrous impacts of floods.

Keywords: flood prevention, civil protection, forecasting, alert system, monitoring system, real-time information delivery, communication infrastructure.
\end{abstract}

\section{Introduction}

High water situations are getting more and more threatening since they occur more and more frequently. Therefore people today are interested in water levels near their home. But it has to be pointed out, that the public view is much more focussed on large rivers and places which are more or less famous or wellknown. However, high water is much more dangerous along small river basins as the period of time between an intense rain and the appearance of a flash flood amounts to just a few hours. So public services have not only to take care about physical flood protection but also the awareness of people near such small rivers, which never thought about rising water levels ten times higher than they were usually. 
When reviewing flood events over the last years then a lot of research has been triggered and new conclusions have been implemented (latest discussion published e.g. in [1-3]), such as,

- research on impacts of global climate change regarding precipitation and snow and glacier smelt;

- research on and development of regional precipitation forecasts;

- investigation and implementation of physical flood protection like building or renewing dams, dikes, sluices or renaturation of river beds;

- build-up or redefinition of information processes and infrastructure;

- acceleration and automation of information processes;

- building public awareness.

With this input from scientific research results and experiences from public safety organisations (PSO) PSI started to build up a new information technology to shorten the period of time between measurement of rising water levels, forecast and actions of PSO and information of the public. To explain, that this is in case of Germany not just a technological problem, but also a political one, we have to have a quick look on the key players in flood protection in Germany.

\subsection{Flood protection authorities in Germany}

The nation of Germany is a federally organized country, split up in 16 federal states (German: Bundesländer). Disaster protection and all kinds of environmental issues, e.g. flood monitoring are within the responsibility of these federal states. But all topics about disaster protection belong to the Ministry of Interior, while the environmental issues belong to the Ministry of Environment. As fortunately not every accident became a large scale disaster the federal states delegated responsibilities in disaster management to the administrative districts (German: Landkreise). On this political level fire workers, rescue services, police and majors deal with disaster management. Each of the administrative districts and federal states, too, focuses, of course, on its own region first.

But nature does not think in terms of political regions, e.g. rivers follow their natural river beds. The Rhine River, one of the longest and most important rivers in Europe, flows through six European countries, five German federal states and lots of German administrative districts.

In consequence of financial and political matters each of the water units of the federal states develops its own flood level monitoring system and operates its own "flood centre". This leads to an open competition between civil authorities in developing the "best" system. Excellent systems are developed by many companies, but sometimes with a different focus. Most of them just provide the information of water levels rising or falling. If any head of a civil protection service want to get this information, he has to get it by himself, via internet, phone or data-transmission.

An answer to that sometimes for non-insiders inscrutable responsibilities is a "flood alerting and information order", as it is implemented in several federal states. It defines the process, how to get information from a "flood information centre" to the public and PSO. 


\subsection{Flood protection as a matter of time}

In case of a flood event a large number of authorities responsible for civil protection have to be alerted quickly. The question of "Who is going to be informed when and by which communication channel by whom" is not only a highly political question but also a very difficult one to answer.

In most of the German municipalities home-grown communication and information technology already exists. At the information chain from gauges measurement technology to phone and fax availability there is a huge variety of technology development from the last 30 years. As a consequence it might happen that there is a perfect structured federal "flood alerting and information order", a modern type of gauge and a working "flood information centre", which cares about the measurement. But in case of a flood warning on Friday evening the information about an upcoming flood is located in front of a fax in the municipal office and nobody recognises until Monday morning.

Building up an information system that monitors water levels in different catchment areas and automatically alerts responsible authorities requires a communication infrastructure that goes far beyond the normal standards in information technology (IT). PSI build up a system like this with "PSIecontrol". Also, the realization with IT has its limits in the event of a real catastrophe.

The quality of real-time system integration is shown by operations handled every day in different communication infrastructures. Where flooding occurs the time between alerting and the actually rising flood is decisive:

- How much time remains for additional flood prevention measures?

- How long is the information chain between recognition of a threatening flood and the last persons affected by it, the citizens?

The period of time between recognition and actual flood depends on the geographic situation, too: in highlands floodwaters rise much faster than in lowlands. In case of a threatening flood time is the most important factor: the period of time between the serious warning that a flood will come and the arrival of the water is the time that can be used for additional measures against the flood.

\section{Information process}

The general information process with PSIecontrol in flood protection is rather straightforward:

- data collection (precipitation, water level, discharge, etc.);

- real-time monitoring of the data;

- $\quad$ alerting (if predefined alarm-levels are exceeded);

- $\quad$ action management by the flood protection units.

There are quite a number of participants involved with various responsibilities such as to supply measurements and prognoses or make decisions and carry out action plans and orders. To give the key player a comprehensive support at their job PSI developed an innovative control centre system called PSIecontrol. 
PSIecontrol is field-tested for supra-regional flood management. Through use of sophisticated modern technology it enables the integration and monitoring of diverse environmental data in real time and when necessary it will initiate detailed alarms.

The key features of the system are:

- fail-safe and failure tolerant system;

- real-time application;

- simple operation;

- fully automated measurement and alarming;

- visual monitoring of message-handling, alarming and archiving.

\subsection{Data collection}

At the start of this information chain weather services play an important part as they forecast precipitation, temperature and sunshine duration. The better the location and the rain intensity are predicted the earlier and more detailed water levels can be computed. In highlands local precipitation forecasts are a real challenge and their impacts can be immense - strong rain on the one or the other side of a hill causes floods in completely different valleys and river catchments. Therefore, precipitation measurements are necessary and decisive in such sensitive areas.

This leads to the next complex task - data collection. Water levels and discharge measurements have to be collected automatically at short time intervals, e.g. every 15 minutes and runoff data have to be computed. As rivers and river systems usually pass different administrative borders a quick and comprehensive cross border data exchange has to be established. In some areas additional human observers are integrated into the information process. These observers look after a water pole and take additional measurements to ensure the quality of all electronic measurements. During past flood events in some cases human observers had to take over completely and provide the measurements since whole measuring stations were flushed away. They can also provide additional observations on water discharge like icing or flotsam washed ashore.

\subsection{Monitoring}

All measurements and observations from all stations have to be checked for measuring or data transmission errors so that only feasible data are stored and used for further processing and actions. A real-time monitoring system is used to check for limiting values, to trigger automatic alarm events and to visualize all necessary data. Based on actual precipitation and runoff data and time series of past days or weeks prognoses of future water levels can be computed.

In case of a threatening or genuine disaster it is important that the hydrologist on duty is provided with general overviews of complete river catchments as well as detailed views of the development of a flood in a specified area. He needs this information to enable him to compile a position report integrating the meteorological and hydrological situation and further developments. 


\subsection{Alerting and information delivery}

As far as the information and communication process is concerned all data and information are available at this point. Now the decisive steps have to be taken: the information must be delivered to all persons concerned. As pointed out in the introduction an information and communication model has to be established stating which information has to be delivered to whom.

Such complex information and communication model can only be implemented when using a powerful and flexible software system which allows an adequate mapping of the defined processes, e.g. comprehensive profile management, individual availability, defining Alarm Channels by Time of Day and Means of Alerting.

And complete automation of the information processes is the key to significantly speeding up the process of warning and alerting citizens and it is the basis of an early warning system. With PSIecontrol information is delivered through different communication channels. Usually it is sufficient to inform the public on a web page or teletext. Depending on gravity, urgency, region, incidence, time of the year or time of the day it is possible to compile the information and deliver directly via the existing information channels such as fax, email, SMS, radio communication of paging systems.

\subsection{Managing the flood: emergency plans}

The last step of the information process presented here consists of the assistance of authorities responsible to manage the flood. In each area potentially affected by a flood action and emergency plans are compiled. These plans usually refer to alarm or water levels of a nearby water level gauge.

Having a communication infrastructure as mentioned above it is only a small technical step to store and maintain these action plans within a software system which automatically alerts recipient groups to execute predefined actions, e.g. road blocks or evacuation of vulnerable places at a certain water level. Again, actions can be monitored and controlled and manual feedback can be integrated into an information process.

With the use of a real-time monitoring and alerting system the period of time can be fully utilized. At the time the flood forecast recognizes an upcoming flood situation on account of water levels and precipitation the information process is set off automatically without any human interaction regardless of the time of day. All relevant persons are informed via their preferred communication channels. Thus the remaining time until the water arrives can be optimized

\section{Example Free State of Saxony}

\subsection{The situation in $\mathbf{2 0 0 2}$}

The flood event in the German Free State of Saxony in summer 2002 did not only leave much damage behind in cities and the countryside in Saxony, it also destroyed the existing infrastructure used for flood warning. The flood warning 
system was literally flooded away. Up to that time Saxony had 3 flood warning centres that were responsible for different river basins. The need for a new technical infrastructure was a chance to renew the organisational structure as well and to introduce forward-looking technical approaches.

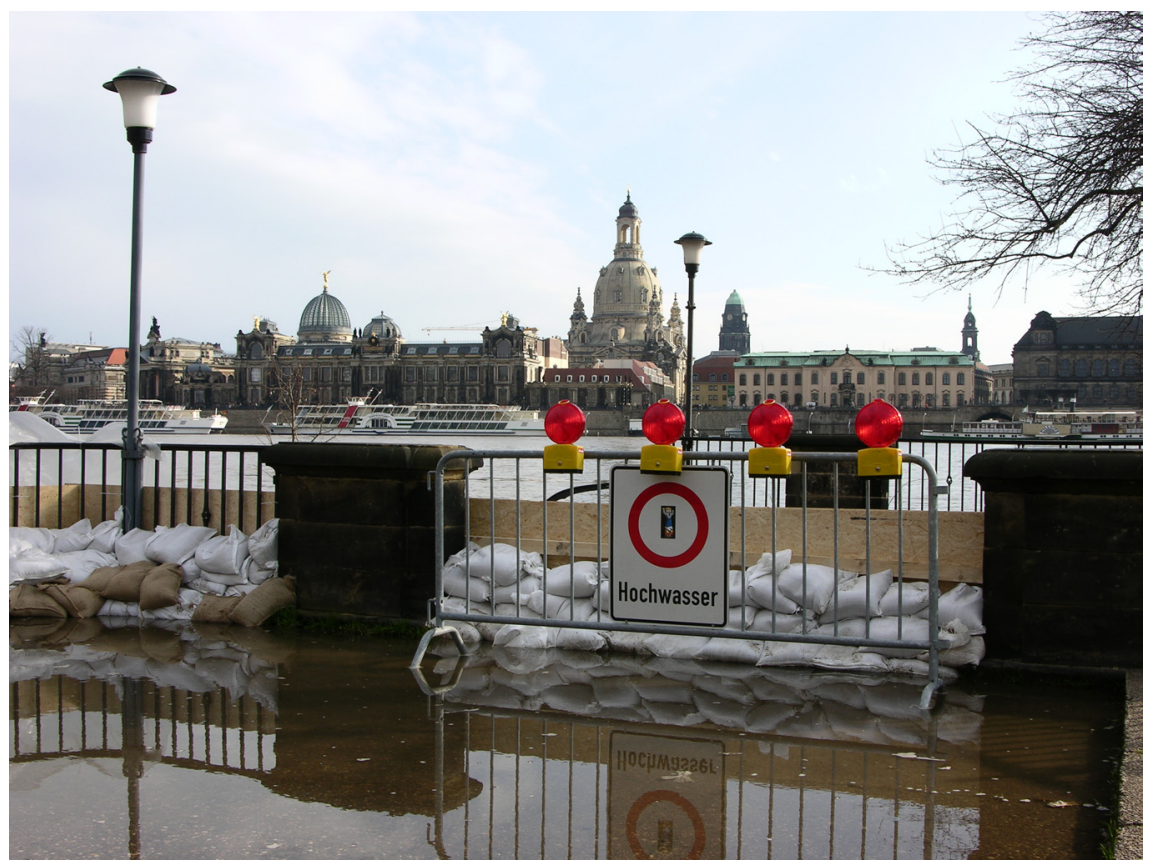

Figure 1: $\quad$ Dresden/Saxony in 2006.

\subsection{Renewing the state's flood water centre}

The renewal of the destroyed flood water infrastructure was accompanied by renewing the whole organization and technique. Initially, the three flood water centres were united and the information infrastructure was renewed.

Having one centre for the whole federal state of Saxony also implied that all person-to-person relationships of the old system had to be replaced by machineman communication. The centre simply does not know any more the persons responsible for taking action in the event of a (threatening) flood.

\subsection{A technical solution}

PSI implemented the technical solution "PSIecontrol" in Saxony. [4] The system is located in the state's flood control centre (Landeshochwasserzentrum). All rivers in Saxony are monitored in real time, predictions on water level developments are made with the help of weather forecasts by the German Weather Service (Deutscher Wetterdienst). 
The System consists of three components: a control unit, an information management system and a communication platform.

- The control unit polls all available control points automatically. Data can be exchanged via voice, web or WAP with enablers on site.

- The information management system is the core of the whole system where all data and documents are stored in redundant and fail safe systems. Analyses, plausibility checks and monitoring of data from all control points are automatically carried out.

- The communication platform is responsible for informing, and when appropriate, initiating an alarm to the appropriate person(s) dependent upon the detected values.

Based on the definitions and experiences made in the German Free State of Saxony the following model is feasible, useful and approved. There are three main types of information or documents:

- management or position reports for each river catchment which covers the meteorological and hydrological situation and include recommendations for actions;

- water level reports which consist of a form containing actual measurements, trends and alarm levels;

- urgent short messages which signal the first-time overrun of the alarm threshold and are replicated in case of transgression of further alarm levels.

The communication model in Saxony is based on the following principles:

- all local partners with responsibilities like mayors, fire or water brigades, police and other safety or rescue services receive directly the above mentioned documents where relevant to their field of responsibility;

- the receipt of an urgent short message has to be confirmed manually so it can be assumed that the content has really been read;

- in case an urgent short message is not confirmed within a defined time span escalation reports are generated and delivered to the supervisory authority;

- all information can be delivered via different and redundant communication channels like fax, email, SMS and voice;

- the public is informed by automatically updated internet and teletext messages.

Manual intervention is also possible if, for example, the operator can anticipate a hazard. Extensive configuration parameters enable very flexible choices as to which information should be conveyed when and to whom and whether it should be passed via fax, email, SMS or voice.

The last major flood event managed by the system occurred in March and April 2006 in Saxony. It was caused by snowmelt and additional precipitation. Within a few hours the water levels of many usually very small rivers rose and flooded streets, villages and landscapes. In this critical situation PSIecontrol managed to issue up to 120 parallel alarms and to deliver up to 8.000 documents within 24 hours. 


\section{Conclusions for the future}

IT solutions are really only a question of technology and can easily be found. A more complicated problem is the definition of communication channels and alert mechanisms. The introduction of systems like PSIecontrol seems to be more complex on the organisational rather than on the technological side.

PSIecontrol itself is rather independent of these questions: due to its adaptability and upgrading functions it can be configured rather easily. Integration of any other technical water level metering equipment with communication protocols is possible. These include alarm channels such as paging devices or even news tickers on TV programs and internet. GIS functionality will be employed for monitoring the alerts as well as for flood maps. PSI develops feasible extensions jointly with local authorities and customers.

The aggregation of various data may be subjected to real-time evaluation for risk analyses and be used for modelling escalation scenarios by an integrated solution. Data-input from air supported dike monitoring enables a real-time dike breach simulation as well as the checking of the water quality. At the same time it provides for harmonising GIS and alarm systems. In future, this information will soundly support necessary decisions.

PSI Environmental Disaster Protection Unit started a project to design a software system which will support hydrologists in flood warning centres as well as local civil protection authorities. It would thus be possible to manage water levels along the river (monitoring, forecasting, alerting) and to support decision makers like mayors in taking the right measures and monitoring progress and success.

\section{References}

[1] Morell, M. et al (eds). BALWOIS 2006 - Abstracts. Conference on water observation and information system for decision support. May 23-26, 2006, Ohrid, Republic of Macedonia. Hydrometeorological Service of Republic of Macedonia, 2006.

[2] Steckeweh, C. (eds). $3^{\text {rd }}$ International Trade Fair and Congress for Flood Prevention, Consequences of Climate Change and Disaster Management. (Plenum II). Flood Protection. Hamburger Messe und Congress GmbH. Hamburg and Berlin. pp. 28-39, 2006.

[3] Steckeweh, C. (eds). $3^{\text {rd }}$ International Trade Fair and Congress for Flood Prevention, Consequences of Climate Change and Disaster Management. (Forum 6). Flood Protection in Municipal Practice. Hamburger Messe und Congress GmbH. Hamburg and Berlin. pp. 96-103, 2006.

[4] Gottwald, S., High Water Monitoring and Warning via PSIecontrol. InterCarto-InterGIS 12 - Proceedings. International Conference on Geoinformation for Sustainable Development. August 28-30, 2006 Berlin, Germany. Eds Kremers, H. \& Tikunov, V. Deutsche Gesellschaft für Kartographie e.V. Berlin, 2006. 